\title{
Associativismo avant la lettre - as sociedades pela abolição da escravidão no Brasil oitocentista
}

ANGELA ALONSO

\section{Resumo}

O artigo contesta a tese da tibieza da vida associativa no Brasil oitocentista, tomando como caso as associações formadas em protesto contra a escravidão no Brasil na segunda metade do século XIX. Contra a tese do insolidarismo, o levantamento do número de associações antiescravistas criadas e da heterogeneidade social de seus participantes denota a exuberância do associativismo no Brasil imperial. Adicionalmente, o artigo argumenta que as inflexões de crescimento e declínio do associativismo abolicionista se explicam por variações nas "oportunidades políticas" (Tarrow, 1998).

Palavras-chave: Associativismo no Brasil oitocentista. Movimento abolicionista. Oportunidades políticas.

\footnotetext{
1 Este artigo é resultado parcial de pesquisa ainda em andamento sobre o movimento abolicionista no Brasil, viabilizado por financiamentos da Fapesp e da Fundação Guggenheim. Agradeço as sugestões do parecerista anônimo de Sociologias.

* Professora do Departamento de Sociologia da USP e pesquisadora do Cebrap.
} 


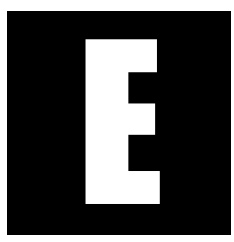

screvendo sobre seu passeio pelos Estados Unidos no século 19, Tocqueville viu graça e desgraça. Terreno de desabrochar do capitalismo, para desesperança do aristocrata, mas também pátria de novidades políticas, uma democracia alicerçada na auto-organização dos cidadãos, sob forma associativa. Além de clássico absoluto, o livro de Tocqueville deu muitas vezes o metro para medir a democracia. Sob essa inspiração é que Putnam andou aferindo volume de associações, desdobrando daí que certas culturas seriam mais propensas que outras a produzir associativismo político no estilo "faça você mesmo", sem se pendurar no Estado.

Dentre nós, a ideia de que certa "cultura política", a "ibérica", teria produzido o oposto do que Tocqueville viu dentre os ianques é recorrente. Oliveira Vianna (1920), em Populações Meridionais no Brasil, deu nome ao complexo que teria viciado a vida política do Império: "insolidarismo social". Desde então, ora o patriarcalismo, ora o patrimonialismo, conforme as preferências teóricas dos intérpretes, aparece como contraponto à tibieza da vida associativa dentre nós. Vis-à-vis a pujança da sociedade civil norte-americana, teríamos tido por cá ausência de associativismo, com a família como único agregado coletivo a fazer face ao Estado.

Pois bem, afirmações desse tipo sobre o passado político brasileiro costumam se amparar em análises de fôlego comprido, mas nem sempre calçadas em levantamento empírico. Poucos são os estudos sobre número e perfil das associações oitocentistas. Conniff (1975) e Jesus (2007) coletaram o número de associações voluntárias oficialmente registradas no fim do Império, mas sem se deter nas especificamente políticas. Já Avritzer (1997) apontou o movimento abolicionista como propulsor de associativismo, mas sem se apoiar em pesquisa de fontes. Meu objetivo aqui é aprofundar essa pista, de modo a argumentar, contra a tese do insolidarismo, a existência de vida associativa no século 19 brasileiro, to- 
mando como caso a mobilização social contra um dos problemas mais espinhosos que o país já enfrentou, a escravidão² ${ }^{2}$

\section{Associativismo abolicionista de elite}

Para vingar, um movimento social precisa fazer jus ao seu adjetivo, acontecendo fora das instituições políticas, e honrar seu substantivo com práticas coletivas: formação de associações e organização de protestos (Tilly, 2005). Por esse critério, o movimento abolicionista brasileiro nasceu quando se fundaram associações civis em seu nome, as quais passaram a organizar eventos de propaganda da causa.

E quando foi isso? Historiando o associativismo brasileiro da Independência aos inícios do Segundo Reinado, Moreira de Azevedo registrou grande variedade de associações. Só para o ano de 1831, fala em "mais de 100" sociedades fundadas (Moreira de Azevedo, 1885, p. 294). Todas basicamente de membros da elite imperial. Infelizmente para os pósteros, Moreira de Azevedo julgou desnecessário seguir seu inventário para além de 1840, daí porque nele não comparece nenhuma associação abolicionista. Jesus (2007, p. 4) iniciou seu levantamento duas décadas depois desse ponto e foi até o fim do Império, descobrindo 177 associações no Rio de Janeiro, conforme registros no Conselho de Estado. Conniff (1970, p.66), que adotou 1880 por ponto de partida, nota que After 1880, many more professionally based mutual aid associations sprang up, tapping less skilled strata of the work force. (...) there were few organizations of employers, and perhaps only a dozen professional groups. Conniff classificou em cinco

2 Meu foco neste artigo são as associações civis públicas criadas pelo movimento abolicionista, o que exclui da análise seja o abolicionismo institucional - parlamentar ou por meio do judiciário -, bem como organizações clandestinas, revoltas de escravos e outras grassroots, atividades que também contribuíram para o fim da escravidão no Brasil. 
tipos as associações voluntárias formalmente registradas no Rio de Janeiro - religiosas, de ajuda mútua, profissionais, de empregados públicos, de trabalhadores e de empregadores -, chegando a 102, em 1879, e 77 "nos anos 1880" (Conniff, 1975, p. 68). Jesus (2007), que quase dobrou esse número, fez classificação parecida. Nenhum dos dois, contudo, menciona associações abolicionistas, embora a literatura específica se refira à profusão delas no Brasil dos anos 1880. A lacuna tem a ver com a fonte. Ambos trabalharam com dados oficiais, sem contabilizar associações que surgiam no espaço público, com manifestos, propaganda na imprensa, eventos, mas sem protocolar sua existência por meio de registro formal.

De seu lado, Avritzer (1997, p. 152) viu o abolicionismo como "o primeiro movimento que representou o surgimento de uma esfera societária" no Brasil, com manifestações públicas, organização de clubes, participação de imprensa e mulheres. Apesar disso, sendo seu apoio empírico justamente Conniff, cujos dados apontam preponderância de associações de base religiosa no Brasil de fins do século 19, concluiu pela fraqueza do associativismo laico brasileiro nesse tempo e "pelo baixíssimo impacto institucional do abolicionismo". Assim, embora admita a conformação progressiva de um plano "societário" a partir de 1850, Avritzer acaba reiterando a tese do insolidarismo, uma "tradição política caracterizada pela falta de densidade no espaço público" - até porque a pujança do associativismo nos anos 1880 contrariaria sua tese de "um novo associativismo civil" de um século depois, no Brasil pós-Redemocratização.

Por fim, a historiografia do abolicionismo brasileiro nunca o tomou como movimento social em sentido rigoroso. O termo aparece frouxo, indefinido, muitas vezes no plural (por exemplo, Machado, 1994; 2009). E a periodização adotada usualmente endossa a datação do fenômeno pelos próprios ativistas - especialmente Nabuco (1900) - fazendo coincidir o início da mobilização com a estreia do próprio Nabuco na política, em 
1879. Os trabalhos recentes que não seguem essa toada pendem para a microhistória local do abolicionismo. São raros e já relativamente antigos os trabalhos de abrangência nacional e fôlego sistematizador (Conrad, 1972; Duque Estrada, 1918; Toplin, 1972). ${ }^{3}$ E nuns como noutros, não há preocupação em coletar o número de organizações formadas em torno da causa. Por tudo isso, pouco se sabe sobre o associativismo abolicionista.

Se, contudo, em vez de registros oficiais, tomarmos por fonte as notícias de fundação de associações abolicionistas veiculadas em panfletos e jornais ${ }^{4}$, o associativismo abolicionista brasileiro se apresenta desde os anos 1840, desenvolvendo-se num crescendo até o fim da escravidão, em 1888.

Tudo começou nos anos 1840, quando um pequeno grupo de ocupantes de postos públicos, diagnosticando a falta de espaço para tratar do fim da escravidão nas instituições políticas, resolveu levar a conversa para fora delas:

O espírito de associação, que nos tempos modernos tão grandemente se tem desenvolvido, veio demonstrar que a reunião quer de forças, quer de capitais, quer de inteligências, é o meio mais eficaz de se vencerem todas as dificuldades respectivas. Se, pois, sociedades filantrópicas se erigissem para a emancipação gradual dos escravos, os seus esforços sistemáticos e perseverantes para obter esse fim, seriam por certo de grande consequência. (Soares, 1847, p. 22)

E foram. Esse associativismo avant la lettre de Caetano Alberto Soares, membro-fundador da Ordem dos Advogados do Brasil, o impulsionou a

3 Para um balanço da literatura sobre abolicionismo no Brasil, veja-se Needell, 2010.

4 A interpretação apresentada a seguir baseia-se em dados coligidos em manifestos, panfletos, jornais (O Abolicionista, de novembro de 1880 a dezembro de 1881; Gazeta da Tarde, de janeiro de 1883 a dezembro de 1886; Cidade do Rio, de outubro de 1887 a maio de 1888; A Redempção, de janeiro de 1887 a maio de 1888) e nos diários de Joaquim Nabuco e André Rebouças. Os dados coligidos a partir dos jornais recobrem, sobretudo, as associações formadas na Corte a partir de 1880, embora tragam informações sobre as províncias. Tanto as associações formadas antes quanto as provinciais e municipais poderão estar, portanto, subrepresentadas nesses dados, limitação que procurei contornar valendo-me de informações presentes na bibliografia secundária. 
organizar com colegas no Rio de Janeiro a Sociedade Contra o Tráfico de Africanos e Promotora da Colonização e da Civilização dos Índios (SCT). Iniciativa que surpreendeu os Quakers John Candler and Wilson Burgess, dois estoicos membros da Religious Society of Friends of Great Britain and Ireland, que visitaram o país em 1852. Deram com uma associação bem estruturada, gerindo jornal, O Philantropo, e 215 membros. Publicara panfleto e havia pouco enviara ao governo projeto de uma lei do Ventre Livre, com desapropriação indenizada da propriedade de escravos (Sctapcci, 1852, p. 30;18), a ser executada por associações particulares - ainda que com recursos do Estado.

A SCT seguia estratégia do abolicionismo anglo-americano de fundar associações civis e com base nelas promover eventos de propaganda dirigidos à sociedade sem mandato, que começavam a chamar de "opinião pública". Os Quakers compareceram a uma das reuniões e se congratularam ao ver a ascensão do assunto ainda melindroso em país que havia pouco abolira o tráfico negreiro (Bethell, 1970) a objeto de debate público fora das instituições políticas:

The fact of the existence of this Society [Contra o Tráfico] in Brazil is important. The alteration of public feeling in regard to Slavery and the Slave-trade is so great, that, although five or six years ago it would not have been tolerated, it now holds its meetings with open doors. (Candler e Burguess, 1852, p. 39).

Tolerada e atrativa para gente variada: militares, estrangeiros, professores primários, advogados, negociantes, médicos, farmacêuticos e até homeopatas, dentre os mais de 300 sócios que chegou a arrebanhar (Kodama, 2008, p. 426;418) e que mantiveram a sociedade ativa até ao menos 1858.

Os Quakers foram dali a Salvador, mas lá bateram nas portas baianas erradas. Ignoraram duas sociedades abolicionistas formadas no ano de 1850. Uma de nome comprido e vida curta: a Sociedade Philantropica Estabelecida na capital da Bahia em benefício dos Brasileiros que tiveram a 
infelicidade de nascer escravos (Graden, 2006, p. 13). A de nome curto foi mais efetiva: a Sociedade Libertadora 2 de Julho queria persuadir senhores a alforrias voluntárias, e seus membros seguiram na campanha abolicionista até seu fim (Fonseca, 1887, p. 244ss).

Se juntarmos o que os Quakers viram no Rio de Janeiro e o que deixaram de ver na Bahia, temos o associativismo abolicionista brasileiro começando autonomamente nas duas maiores cidades do Império. Coisa pouca é verdade, mas que daí por diante encorpou. Quem viu a marola abolicionista brasileira dos anos 1850 não imaginaria o tsunami dos 1880 .

Se os Quakers tivessem voltado ao país nos anos 1860 dariam com semente germinada. Vertebrava-se um espaço público não parlamentar de debate sobre a escravidão no Brasil, e o abolicionismo ganhava forma associativa.

Isso porque nessa hora mudavam as oportunidades políticas ${ }^{5}$ (Tarrow, 1998). Quando o Norte abolicionista venceu a guerra norte-americana, em 1865, outros vizinhos se puseram a desarrear suas carruagens escravistas: a Espanha pôs para andar lei de libertação dos ventres e dos velhos para suas colônias escravistas na América. Com duas das três grandes economias de plantation, Estados Unidos e Cuba, encaminhando o emancipacionismo, o Brasil viu o prenúncio de morrer sozinho na praia escravista.

Domesticamente, o ano de 1868 abre período de radicalização Liberal, quando o partido, derrubado do comando do gabinete pelo poder moderador, embora tivesse maioria na Câmara, reagiu usando o espaço

\footnotetext{
5 Tarrow (1998, p. 20) argumenta que movimentos sociais surgem tipicamente quando há aumento de permeabilidade das oportunidades políticas, isto é, alterações nas dimensões formais e informais do ambiente político que aumentam as possibilidades de expressão pública de reivindicações de grupos sociais outsiders em relação ao arranjo político principal. Essas alterações incluem crises na coalizão política no poder, redução da repressão e presença de aliados potenciais, como partidos políticos, mídia e elites dissidentes. Recentemente, o próprio Tarrow (2010) ampliou o escopo do conceito para incluir mudanças no ambiente político internacional.
} 
público para protestar contra o novo estado de coisas. Os Liberais Radicais, mostrou José Murilo de Carvalho (2007), se lançaram na cena não parlamentar, com manifestos, jornais, clubes e conferências proselitistas de protesto e de reformas. Uma delas era a abolição gradual, inscrita no Manifesto Liberal de 1869.

Ao usarem o espaço público como lócus para criticar o sistema político, os Liberais legitimaram ações de mesmo tipo por parte de atores alijados pelo sistema político, suscitando um efeito demonstração. Supunham talvez se cacifar e tornar fortalecidos às instituições. Mas atraindo novos atores para a conversa, abriram porteira que o sistema político imperial nunca mais pôde fechar.

Conjuntura externa e interna somadas soaram o alarme nas instituições políticas imperiais. O silêncio tácito depois do fim do tráfico se rompeu, e a abolição gradual da escravidão subiu a objeto de deliberação em meados dos anos 1860. Mas dilacerada entre postergar e agir, a elite imperial rachou. A luta entre modernizadores e refratários culminou na aprovação da Lei do Ventre Livre, mas explodiu o dique estamental da política do Império, com o debate extravasando as instituições políticas.

Essa conjuntura de mudança na cena internacional, uso do espaço público pelos Liberais Radicais mais crise no sistema político imperial conformaram oportunidades políticas para que o associativismo abolicionista crescesse e se diversificasse na segunda metade dos anos 1860. Valendose dos meios de vocalização dos Liberais e explorando a cisão da elite política, um primeiro pico de formação de associações abolicionistas, modesto, aconteceu entre 1868 e 1871.

Iniciativas nessa direção nasceram do seio da própria elite imperial. Caso do educador-modelo do Império, o mineiro Abílio César Borges (1824 -1891), amigo de modernidades que lotavam suas malas de viagens a congressos no estrangeiro (Gondra e Sampaio, 2010) e que orientavam 
seu Ginásio Bahiano, em Salvador, de 1858 a 1870, cujos alunos, como Castro Alves e Rui Barbosa, e professores, caso de Teodoro Sampaio (Alves, 1942 , p. $128 ; 131 ; 118 \mathrm{ss})$, deram todos em abolicionistas.

É que, julgando o patriotismo parte do que devia ensinar (Alves, 1942, p. 142-3), Borges propagandeou o fim da escravidão (Gondra e Sampaio, 2010, p. 78). Herdeiro da causa da SCT e fomentador dela dentre os jovens, Borges foi um conector geracional, socializando os jovens de fins dos anos 1860 nas formas de ação dos anos 1850. Carregando a Independência no nome, a Sociedade Libertadora Sete de Setembro, que fundou em 1869, tinha nada menos que 512 sócios (Fonseca, 1887, p. 248), muitos deles alunos e professores de seu colégio, com a novidade de 15 mulheres. Quase toda essa gente vinha da elite social, como o próprio Borges, logo Barão de Macaúbas, e o político liberal Manuel de Souza Dantas, que reencontraremos adiante.

A Sete de Setembro organizava eventos de propaganda. O mesmo fazia a Sociedade Promotora de Emancipação de Escravos na Província do Rio Grande do Sul, liderada pelo engenheiro hidráulico e homem de negócios João Driesel Frick (1839-1909). De ascendência suíça, português de nascimento, radicado em Pelotas, mas tendo vivido dois anos em Londres (Xavier, 2010, p. 60), trouxe a abolição na cabeça. Com o médico João Landell, organizou, também em 1869, a associação que reunia semanalmente os 160 sócios, muitos estrangeiros, de Montevidéu, Zurique, Hamburgo, Lisboa e várias cidades da Inglaterra, e incluindo ao menos seis mulheres (Frick, 1885, p. $21 ; 18 ; 25-6$ ). Assim como a Sete de Setembro, a Promotora da Emancipação fazia cerimônias de propaganda por uma Lei do Ventre Livre (Frick, 1885, p. 16).

Toada parecida saía pela boca cearense de Adolfo Bezerra de Menezes (1831-1900), o espírita brasileiro. Além dessa prerrogativa, era político do Partido Liberal, que, em 1869, publicou A Escravidão no Brasil 
e as medidas que convém tomar para extingui-la sem dano para a nação, folheto que é a cara da década: crítica moderada à escravidão mais projeto de emancipação gradual. O médico acusava o governo de reter o carro da história e defendia a auto-organização da sociedade, para apressar a marcha da civilização e do Ventre Livre:

Fique o governo em sua eterna impassibilidade, vamos nós simples cidadãos, mas dedicados obreiros do progresso de nossa terra; espalhando a semente por todos os ângulos do império, que um dia virá em que do Norte ao Sul um brado de indignação, partido de todos os peitos brasileiros, levará de vencida a inércia de uns, e o emperramento de outros, e dará ao mundo o exemplo grandioso de um povo marchando adiante de seu governo na iniciação e promoção das grandes reformas que a civilização do nosso século reclama. (Bezerra de Menezes, 1869, p. 50).

Por lacuna de política de Estado, a estratégia seria a formação de associações civis..

Nisto o baiano Borges e o gaúcho Frick não estavam sozinhos. Ao menos 18 associações de mesmo padrão apareceram de meados dos anos 1860 até 1871, 3 na Bahia; 2 no Ceará, 2 em Pernambuco; Maranhão, Amazonas e Piauí ficaram com uma cada. Essa distribuição alimentaria a tese de Conrad (1972) de que o abolicionismo era coisa do Norte despovoado de escravos contra um Sul escravista, não fosse o fato de a distribuição ser meio a meio: na nomenclatura do Segundo Reinado, 8 no Sul, contrabalançando as 10 do Norte - e 5 em São Paulo, onde a economia do café explodia. 
Quadro 1: Associações Abolicionistas no Brasil - 1860 a 1871

\begin{tabular}{|l|c|}
\hline \multicolumn{1}{|c|}{ Associação } & Província \\
\hline Sociedade Emancipadora Amazonense & Amazonas \\
\hline Sociedade Humanitária Abolicionista & Bahia \\
\hline Sociedade Libertadora Sete de Setembro & Bahia \\
\hline Sociedade Abolicionista Comercial & Bahia \\
\hline Sociedade Libertadora de Baturité & Ceará \\
\hline Sociedade Manumissora Sobralense & Ceará \\
\hline Sociedade Manumissora 28 de Julho & Maranhão \\
\hline Sociedade Emancipadora & Pernambuco \\
\hline Sociedade Humanitária e Libertadora Nazarense & Pernambuco \\
\hline Sociedade Emancipadora do Piauí & Piauí \\
\hline Emancipadora Campista & Rio de Janeiro \\
\hline Sociedade da Libertação & Rio de Janeiro \\
\hline $\begin{array}{l}\text { Sociedade Promotora de Emancipação de Escravos na Província do } \\
\text { Rio Grande do Sul }\end{array}$ & Rio Grande do Sul \\
\hline Sociedade Abolicionista Fraternização & São Paulo \\
\hline Sociedade Esperança & São Paulo \\
\hline Sociedade Emancipadora Fraternização Primeira & São Paulo \\
\hline Sociedade Redentora da Criança Escrava & São Paulo \\
\hline Emancipadora & São Paulo \\
\hline
\end{tabular}

Fontes: informações recolhidas em Azevedo, 1999; Dantas, 1988; Ferreira, 1999; Fonseca, 1887; Frick, 1885; Hahner, 1990; Brito, 2003; Morel, 1967; Mott, 1988; Moura, 2004; Santos, 2008.

Nessa lista há variedade, mas nada dissonante do tom de Borges e Fricks: associativismo de elite, ao largo de partidos e instituições políticas, mas em relação ambivalente com eles - contestando sem revolucionar. Associativismo ordeiro em forma e objetivos, de corte liberal, mas avançando paralelo ao Parlamento, usando o espaço público para espalhar panfletos, jornais e cerimônias públicas de ritualização da entrega de cartas de liberdade adquiridas com as doações arrecadadas. E inovando na cena brasileira ao induzir a participação feminina na política. É esse o 
estilo de ativismo que compõe a onda de mobilização abolicionista que antecede a aprovação da Lei do Ventre Livre no Parlamento.

\section{O abolicionismo das ruas}

Depois da Lei do Ventre Livre aprovada, em 1871, o ímpeto de criação de sociedades abolicionistas de elite arrefeceu. Mas a nova configuração fez prosperar outro gênero de associativismo abolicionista, mais popular, desabrochado a partir de novas mudanças nas oportunidades políticas.

O Ventre Livre criou caminhos para que a mobilização abolicionista ganhasse escala, em dois sentidos. De um lado, o Fundo de Emancipação gerido pelo Estado, que a lei instituía, estabeleceu o direito do escravo se libertar formando um "pecúlio". A possibilidade de autocompra legalizou e estimulou a multiplicação do que os abolicionistas até então já praticavam: a auto-organização da sociedade, formando associações para batalhar donativos e assim comprar alforrias. Isto é, o que antes se fazia em pequena escala a despeito do Estado, poderia agora se multiplicar, sob amparo da lei e, eventualmente, de recursos públicos.

De outro lado, a tramitação parlamentar da lei de 1871 produziu crise política. A cizânia entre e intrapartidos apareceu e querelas na imprensa, em panfletos, na Corte, como em várias províncias. Os Liberais, então fora do governo, criticaram as instituições dos Conservadores, em jornais e conferências, propagando agenda reformista. Os mais exaltados preferiram compor partido antirregime, o Republicano, em 1870, que atiçou o pequeno espaço público com mais jornais, clubes e conferências, chamando para a política jovens que doutro modo não entrariam nela por falta de estirpe, como Luiz Gama, em São Paulo, e José do Patrocínio, na Corte.

Esse contingente de moços com "disponibilidade biográfica" (McAdam, 1986) para a política tem a ver também com o êxito do gabinete Rio Branco em algumas tarefas da modernização. Aproveitando a potência da 
economia do café, secundou o Ventre Livre com incentivo a negócios e melhoria da infraestrutura urbana, barateamento de máquinas e ampliação do acesso às faculdades. A capital do Império, as cidades maiores, Recife e Salvador, e mesmo as pasmacentas São Paulo e Porto Alegre foram sacudidas pela modernização, que dinamizou a vida intelectual e artística e fomentou uma nova imprensa, alargando as possibilidades de debate de questões públicas (Alonso, 2002).

O coquetel crise-e-reforma democratizou o protesto abolicionista, até então restrito ao círculo da aristocracia e das instituições políticas. Converteram-se em ativistas muitos beneficiários da reforma das faculdades imperiais, agora porosas à ascensão social pelos estudos, como também jornalistas, tipógrafos, desenhistas e escritores, que os novos jornais empregavam; artistas, instrumentistas, cantores, atrizes, comediantes, compositores, em busca de lugar na pequena indústria de entretenimento da Corte. Sem chances de alcançar o Parlamento, adentraram debate político, pela via da imprensa de porte médio e pela formação de associações.

Movimentação que ganhou momentum em 1878, hora de mudanças nas oportunidades políticas, por conta da troca de dominação partidária no sistema político. Os Liberais assumiam o governo, depois de década inteira fora dele. Configuração interpretada pela nova geração como permeabilidade do sistema político a mudanças. Os grupos alijados da cena política principal, como o self-made-man José do Patrocínio, viram ocasião para fazer cena paralela, com as associações e os jornais. Usuários dos mesmos recursos em seu ostracismo político, comprometidos com programa de reformas e críticos dos métodos violentos dos Conservadores, os Liberais chegando ao governo estavam - ao menos moralmente - impedidos de reprimir eventos de mobilização tão legítimos quanto os seus próprios. Assim a ascensão liberal foi interpretada: como ampliação de oportunidades para expressão de pleitos políticos e diminuição de ameaças de repressão. Campo no qual o associativismo abolicionista poderia se desenvolver e pressionar pela tramitação parlamentar da abolição. 
Além disso, havia expectativas de que, tendo tematizado o fim progressivo da escravidão quando oposição, os Liberais trariam a questão de volta à agenda sendo governo. $\mathrm{E}$ de fato o tema voltou, embora não por mãos do executivo, mas por ala do Partido Liberal, no que ajudou a audácia de um deputado estreante, que a vocalizou no Parlamento. Em 1880, Joaquim Nabuco apresentou projeto de abolição gradual. O fato do herdeiro de um dos líderes do Partido Liberal chamar para si a bandeira na Câmara indicou a existência de aliados da causa dentro das instituições políticas, abrindo a possibilidade de construção de aliança entre abolicionismo parlamentar e societário. O deputado buscou sustentação no associativismo abolicionista, e sua atuação no Parlamento suscitou mais associativismo (Alonso, 2010).

A situação liberal de 1878 a 1885 deu, pois, as oportunidades políticas para a expansão do associativismo, desencadeando a maior e mais diversificada onda de mobilização abolicionista, que ultrapassou seu perímetro original, a elite social.

Quadro 2 - Associações abolicionistas fundadas por período, 1868-1888

\begin{tabular}{|l|c|}
\hline \multicolumn{1}{|c|}{ Períodos } & Número de Associações \\
\hline $\begin{array}{l}\text { Radicalização Liberal durante situação Conservadora Pré-Ventre } \\
\text { Livre (1868-1871) } \\
\text { Situação Conservadora Pós-Ventre (1872-1877) }\end{array}$ & 19 \\
\hline Situação Liberal (1878-1885) & 87 \\
\hline Situação Conservadora (1885-1888) & 19 \\
Total (1868 -1888) & 129 \\
\hline
\end{tabular}

Fontes: Dados coligidos a partir dos jornais O Abolicionista, de novembro de 1880 a dezembro de 1881; Gazeta da Tarde, de janeiro de 1883 a dezembro de 1886; Cidade do Rio, de outubro de 1887 a maio de 1888; A Redempção, de janeiro de 1887 a maio de 1888; do Manifesto da Confederação Abolicionista, 1883; e complementados com informações de Alonso, 2002; Castilho, 2008; Conrad 1972; Duque Estrada, 1918; Ferreira, 1999; Figueroa, 2007, Fonseca, 1887; Hahner, 1990; kittleson, 2005; Loner, 1999; Machado, 1994; Morel, 1967; Moura 2004; Mott, 1988; Moraes, 1924; Rolim, 2002, Santos, 2008; Schiavon, 2009; Schumaher e Brazil, 2000. 
O fato da maior parte das associações abolicionistas ter se formado no curso da situação liberal não significava alinhamento entre o movimento e o partido. A relação com o Partido Liberal é fato estampado na proximidade de Patrocínio, Nabuco e Gama, líderes abolicionistas, com políticos liberais; os três entraram na vida pública puxados por essas mãos. Contudo, havia também membros do Partido Conservador no movimento, o caso de Antonio Pinto, de Gusmão Lobo e de Antonio Bento, líder em São Paulo. E porção bem considerável dos abolicionistas não ficava de um lado, nem do outro: eram republicanos. Muitas vezes, os abolicionistas se apresentavam como se compusessem partido autônomo ou movimento suprapartidário, o que era mais o caso. Essa atuação independente se praticou em situações decisivas, com apoio massivo do movimento tanto a governos Liberais - o de Manuel de Souza Dantas (1884-1885) -, quanto a Conservadores - o de João Alfredo (1888) quando comprometidos com medidas abolicionistas.

\subsection{O batalhão da Confederação}

Interpretando as oportunidades políticas abertas com a ascensão liberal ao poder de 1878 como auspiciosas para a abolição, três negros se puseram a fazer mobilizações públicas coletivas na Corte para pressionar o parlamento nessa direção: o jornalista José do Patrocínio, dono da Gazeta da Tarde; o médico Vicente de Souza, professor da Escola Normal, e o engenheiro-empresário André Rebouças. Foram apadrinhados pelo conselheiro Nicolau Joaquim Moreira, experiente em associativismo, membro que era, como Rebouças, de uma das mais sólidas e longevas associações no Império, a Sociedade Auxiliadora da Indústria (SAIN), frequentada por nata de modernizadores, inclusive os membros da SCI (Moreira de Azevedo, 1885, p. 315). Moreira funcionou como conector geracional, tal qual Abílio Borges, entre o ativismo abolicionista de elite dos anos 1860 e a mobilização popular da década de 1880 . 
Rebouças, Souza e Patrocínio começaram, em 1879, com conferências de propaganda, nas quais recolhiam fundos e ritualizavam o fim da escravidão, em um desenvolvimento da estratégia Borges e inspirados em precedentes domésticos - as conferências Liberais Radicais, as científicas e as "populares" da Glória - e estrangeiros - as conferências abolicionistas inglesas, norte-americanas e espanholas. Mas deram a elas novo tom. As conferências abolicionistas sediaram-se em teatros, recorrendo às artes como forma de atração e sensibilização do público urbano para os horrores da escravidão. Essas "conferências-concerto" se consagraram como fórmula matter da propaganda abolicionista (Alonso, 2011), eventos de mobilização da opinião pública e de endosso a iniciativas abolicionistas, como a de Nabuco, no interior do sistema político.

Rebouças, Souza e Patrocínio logo vertebraram essa mobilização. Em 1880, criaram a Associação Central Emancipadora (ACE). No mesmo ano, Nabuco, também de par com Rebouças, deu passo idêntico, formando a Sociedade Brasileira Contra a Escravidão (SBCE). A ACE juntava gente de fora do sistema político. Já a SBCE seguia os moldes canônicos da política aristocrática, ficando mais perto da Libertadora Sete de Setembro, da qual replicava até o título do periódico, O Abolicionista. Com a agremiação, Nabuco consolidava sua posição de broker entre o parlamento e o ativismo social (Alonso, 2010). A ACE nasceu em teatro, a SBCE, na sala de visitas dos Nabuco. Mas em ambas estava André Rebouças, que aproximou os dois estilos de ativismo, o de elite e o popular, combinação encarnada em sua pessoa: ao mesmo tempo aristocrata e descendente de africanos.

Nem a ACE, nem a SBCE cresceram como a Libertadora Sete de Setembro em número de sócios. Em vez de poucas e grandes associações, como nos anos 1860 e 1870, a estratégia da década de 1880 foi inversa: agremiações nanicas, mas abundantes, com gente variada, dando efeito de volume ao movimento. Durante esses anos, as organizações abolicionistas cresceram e se espalharam pelo país, em andamento parecido ao 
do movimento hispânico, produtor de boom associativista na Madrid dos anos 1870 (Schmidt-Nowara, 1999).

Rebouças e Patrocínio consolidaram o volume primeiro em um "Congresso Abolicionista do Rio de Janeiro", no qual agregaram 11 associações (Gazeta da Tarde, 10/5/1883). Com adesão de mais duas, nasceu, com manifesto pela abolição imediata e sem indenização, a 11 de agosto 1883, a Confederação Abolicionista (CA):

Quadro 3 - Associações congregadas na Confederação Abolicionista - 1883

\begin{tabular}{|l|l|}
\hline \multicolumn{1}{|c|}{ Associação } & Província representada \\
\hline Abolicionista Cearense & Ceará \\
\hline Abolicionista Espírito-Santense & Espírito Santo \\
Libertadora Pernambucana & Pernambuco \\
Caixa Abolicionista Joaquim Nabuco & Rio de Janeiro \\
Caixa Libertadora José do Patrocínio & Rio de Janeiro \\
Centro Abolicionista Ferreira de Menezes & Rio de Janeiro \\
Club Abolicionista Gutenberg & Rio de Janeiro \\
Club dos Libertos de Niteroy & Rio de Janeiro \\
Clube Abolicionista dos Empregados do Comércio & Rio de Janeiro \\
Clube Tiradentes & Rio de Janeiro \\
Libertadora da Escola de Medicina & Rio de Janeiro \\
Libertadora da Escola Militar & Rio de Janeiro \\
Sociedade Brasileira Contra a Escravidão & Rio de Janeiro \\
Sociedade Libertadora Sul-Rio-Grandense & Rio Grande do Sul \\
\hline
\end{tabular}

Fonte: Manifesto da Confederação Abolicionista do Rio de Janeiro, RJ, 1883

Uma sequência de adesões fez a CA chegar a 20 grupos-membros ainda no primeiro ano de vida. A estratégia era dupla. De uma parte, seguia a propaganda, publicando panfletos e organizando conferênciasconcerto. De outra, chamou para si a concatenação de sociedades, eventos e publicações abolicionistas, dispersos Império afora. Nem todo mun- 
do vestiu essa camisa. Como sói acontecer em movimentos sociais, havia facções, conflitos e dissidências, mas a CA logrou albergar toda a movimentação relevante na Corte e fez parcerias com o que havia de mais expressivo nas províncias. Direta ou indiretamente, fomentou ativismo, com viagens de proselitismo, e apadrinhou iniciativas locais, envolvendose em praticamente todos os eventos abolicionistas relevantes desde seu surgimento até o fim da escravidão.

O crescimento do abolicionismo não foi só de apoio público, foi também expansão literal, geográfica. Embora concentrado na Corte, capital cultural, econômica e - para nosso assunto o mais importante - política do país, o abolicionismo extrapolou o Rio de Janeiro. Já nos anos 1850, as associações abolicionistas surgiram simultaneamente em duas províncias e pós-Ventre Livre tomaram nove.

Da ascensão de uma situação Liberal em 1878 até sua queda em 1885, o Rio de Janeiro se conservou polo principal, com 25 das 87 associações antiescravistas surgidas no país nesses 7 anos. Mas duas outras províncias tiveram pico associativo: Amazonas, onde surgiram 10 novas associações, e Ceará, onde se formaram 12. Nesses casos, o crescimento muito se deveu à estratégia nacional da CA de concentrar a campanha nas províncias em que a escravidão era pouco importante economicamente, com pequeno contingente de escravos. O mesmo vale, com menor empenho, para o Rio Grande do Sul, onde surgiram 8 novas sociedades. Mas também houve movimentação relevante no coração do escravismo: em São Paulo, surgiram 7 novas sociedades - foi onde, em 1882, Luiz Gama formou o Centro Abolicionista de São Paulo. Em todos esses casos também, a dominação liberal no governo central reforçou tendência associativa anterior: eram províncias que tinham sediado as primeiras associações abolicionistas nos anos 1860. Noutras partes, as novas oportunidades políticas nacionais é que suscitaram abolicionismo onde ele antes não existia: por 
exemplo, depois da ascensão do Partido Liberal ao gabinete, em 1878, é que surgiram as primeiras associações abolicionistas em Goiás, a Sociedade Emancipadora Goiana (1879), e no Pará, a Liga Libertadora (1878). Seja reforçando o que existia, seja estimulando associativismo ab ovo, seja como iniciativa local, seja como difusionismo da CA, o fato é que durante a dominação Liberal o movimento abolicionista alcançou nacionalização, com associações funcionando em 15 das 20 províncias do Império.

\subsection{Os ativistas}

Se até os anos 1870, com exceções que ratificam a regra, o abolicionismo era circunscrito à elite imperial, a partir de 1878, ganha heterogeneidade social. Sem perder setores da elite social, que Joaquim Nabuco seguiu agregando, o movimento se adensou com ativistas de estratos sociais médios e mesmo baixos.

A diversificação de apoio social ao abolicionismo tem a ver com o processo de modernização que atingiu o país pelos anos 1870, mas também com o fim do tráfico negreiro. Quando a entrada de africanos estancou, o escravo, antes mercadoria acessível à maior parte da população, virou bem precioso, cuja posse concentrou-se nas famílias de mais renda e nas regiões vinculadas ao agronegócio. Desde aí havia um grande contingente de famílias no país com poucos ou nenhum escravo e, portanto, sem interesse econômico direto na manutenção da escravidão. Daí a ampla base social potencial que o movimento abolicionista podia tentar conquistar.

Em busca de persuadi-la, saíram os líderes do abolicionismo das ruas do Rio de Janeiro, que eram três escolas. Rebouças era professor da Politécnica, Vicente de Souza, da Escola Normal, e Patrocínio, além de egresso da Medicina, ajuntava em seu jornal, A Gazeta da Tarde, escritores e profissionais de teatro. Imerso nessas redes sociais, o trio atraiu para o movimento estudantes, professores, artistas, jornalistas, profissionais libe- 
rais. O presidente da Confederação Abolicionista, João Clapp, dono de loja de porcelana, agregava ainda pequenos comerciantes.

Quanta penetração social o movimento alcançou de fato pode se aferir pela profissão de 254 abolicionistas atuantes no Rio de Janeiro entre 1880 e 1888. Bergstresser (1973, p. 51), que fez o levantamento, identificou empregados públicos, advogados, homens de negócio, da Marinha e do Exército, engenheiros, cientistas, farmacêuticos, dentistas, tipógrafos, jornalistas, escritores, professores de escola pública, solicitadores, músicos, e até mesmo senadores, deputados e um fazendeiro. E, lendo a Gazeta da Tarde, ao longo dos anos 1880, encontram-se ainda dentre os membros das associações abolicionistas: professores de faculdade; empregados do comércio; imigrantes portugueses; artistas de teatro; mulheres; negros e mestiços livres ou libertos; crianças; e até um Club Abolicionista dos Cozinheiros e Copeiros Confederados, que mudou depois seu nome para Club Abolicionista da Classe Culinária Confederada. 
Quadro 4 - Perfil dos Membros de Associações Abolicionistas do Rio de Janeiro - 1878$1884^{6}$

\begin{tabular}{|l|c|c|}
\hline \multicolumn{1}{|c|}{ Associação } & Ano & Perfil \\
\hline Centro Abolicionista Forense & 1883 & Advogados \\
\hline Club dos Advogados Contra a Escravidão & 1884 & $\begin{array}{c}\text { Advogados } \\
\text { Advogados, políticos } \\
\text { e jornalistas }\end{array}$ \\
$\begin{array}{l}\text { Sociedade Brasileira Contra a Escravidão } \\
\text { Caixa Emancipadora do Club Vasques }\end{array}$ & 1880 & Artistas de teatro \\
$\begin{array}{l}\text { Club Abolicionista dos Cozinheiros e Co- } \\
\text { peiros Confederados [Club Abolicionista } \\
\text { da Classe Culinária Confederada] }\end{array}$ & 1883 & Cozinheiros \\
$\begin{array}{l}\text { Clube Infantil Libertador } \\
\text { Sociedade de Meninos }\end{array}$ & 1883 & Crianças \\
$\begin{array}{l}\text { Club dos Abolicionistas Empregados } \\
\text { do Comércio }\end{array}$ & 1883 & Crianças \\
$\begin{array}{l}\text { Caixa de Donativos do Congresso } \\
\text { Literário Guarany }\end{array}$ & 1883 & Empregados do comércio \\
$\begin{array}{l}\text { Libertadora 28 de Setembro } \\
\begin{array}{l}\text { Sociedade para a Libertação dos } \\
\text { Escravos na Escola Militar do R.Janeiro }\end{array}\end{array}$ & 1883 & Estudantes de colégio \\
\hline $\begin{array}{l}\text { Sociedade Abolicionista Luso Brazileira } \\
\text { Clube dos Libertos contra a Escravidão }\end{array}$ & 1883 & Estudantes de faculdade \\
\hline
\end{tabular}

Fonte: Gazeta da Tarde, 1880;1881;1882;1883;1884

Além da multiplicidade social, as associações exibem a inclusão política de gênero. Sendo o direito de voto vedado ao "sexo gentil", sua presença no movimento é por si de monta. As mulheres adentraram o assunto por três portas. A canônica era a da filantropia: a sociedade escravocrata liberava as senhoras de alta extração do serviço doméstico, sem abrir-Ihe carreiras; tempo livre dedicado a causas cristãs e beneméritas,

6 O Clube Infantil Libertador e o Clube José do Patrocínio aparecem com uma interrogação, porque não foi possível aferir com segurança o ano preciso de sua fundação. O mesmo vale para o próximo quadro. 
pelas quais nasceram associações dedicadas especificamente à libertação de crianças e de escravas. Esse foi o caso, por exemplo, da Sociedade Redentora da Criança Escrava, fundada em São Paulo pela senhora Martim Francisco. Outra possibilidade foi entrar de braço com marido, pai ou irmão abolicionista, viela frequente, com os abolicionistas carregando para a política as mulheres da família. Assim nasceu o Club José do Patrocínio, liderado por sua esposa. A terceira via foi a das artistas, escritoras e principalmente cantoras e atrizes, mulheres livres dos impedimentos da família tradicional, que entraram pela porta do teatro. Assim foi com Luiza Regadas, o "rouxinol abolicionista", e com Chiquinha Gonzaga.

Havia sim hierarquia entre os e as abolicionistas. Em uma sociedade tradicional, a distinção de gênero é crucial. Mas os abolicionistas produziram uma politicização da vida privada, envolvendo mulheres e crianças na propaganda, por exemplo, caso da "matinée musicale" totalmente feminina, que João Clapp organizou no Rio de Janeiro, em 6 de fevereiro de 1881 (Associação Central Emancipadora, Boletim n.8, 20/3/1881, p. 19).

Muitas dessas mulheres tomaram parte ativa em associações masculinas ou criaram suas próprias. Não só na capital, onde se suporia maior tolerância. Pelo menos 26 sociedades abolicionistas femininas se formaram ao longo da campanha, situadas em 10 das 20 províncias do Império; 18 delas exclusivamente de mulheres. 
Quadro 5 - Associações Abolicionistas Femininas ou Mistas no Brasil - 1868-1888

\begin{tabular}{|c|c|c|c|}
\hline Associação & Composição & Fundação & Província \\
\hline Sociedade Esperança & feminina & 1867 & São Paulo \\
\hline Associação Protetora dos Escravos & feminina & 1882 & São Paulo \\
\hline Cearenses Libertadoras & feminina & 1882 & Ceará \\
\hline Aurora Redemtora & feminina & 1883 & Ceará \\
\hline As Baturiteenses Libertadoras & feminina & 1883 & Ceará \\
\hline As Libertadoras Messejanenses & feminina & $1883(?)$ & Ceará \\
\hline Associação de Senhoras Abolicionistas & feminina & 1883 & Rio de Janeiro \\
\hline Centro Abolicionista de Porto Alegre & feminina & 1883 & Rio Grande do Sul \\
\hline $\begin{array}{l}\text { Club Carlos Gomes, sociedade feminina } \\
\text { e musical }\end{array}$ & feminina & 1883 & Rio de Janeiro \\
\hline $\begin{array}{l}\text { Libertadoras, sociedade abolicionista de } \\
\text { senhoras }\end{array}$ & feminina & 1883 & Rio de Janeiro \\
\hline $\begin{array}{l}\text { Sociedade Libertadora de Senhoras de S. } \\
\text { Francisco }\end{array}$ & feminina & 1883 & Ceará \\
\hline Clube José do Patrocínio & feminina & $1883(?)$ & Rio de Janeiro \\
\hline Amazonenses Libertadoras & feminina & 1884 & Amazonas \\
\hline Sociedade Abolicionista Ave Libertas & feminina & 1884 & Pernambuco \\
\hline Sociedade Abolicionista 28 de Novembro & feminina & 1884 & Rio Grande do Sul \\
\hline Comissão de Libertadoras & feminina & $188 ?$ & Rio Grande do Norte \\
\hline Club Abolicionista Feminino & feminina & 1885 & Rio de Janeiro \\
\hline Associações de Mulheres Abolicionistas & feminina & 1887 & São Paulo \\
\hline Sociedade Libertadora Sete de Setembro & mista & 1869 & Bahia \\
\hline Sociedade Redentora da Criança Escrava & mista & 1870 & São Paulo \\
\hline Emancipadora & mista & 1871 & São Paulo \\
\hline Sociedade da Libertação & mista & 1871 & Rio de Janeiro \\
\hline Emancipadora Parahybana & mista & 1873 & Paraíba \\
\hline $\begin{array}{l}\text { Sociedade Libertadora Aracajuana Caba- } \\
\text { na do Pai Thomaz }\end{array}$ & mista & 1882 & Sergipe \\
\hline Clube do Cupim & mista & 1887 & Pernambuco \\
\hline Clube Castro Alves & mista & 1888 & Bahia \\
\hline
\end{tabular}

Fontes: Conrad 1975; Ferreira, 1999; Fonseca, 1887; Figueroa, 2007; Gazeta da Tarde; Hahner,1990 Kittleson, 2005; Mott, 1988; Moura 2004 Schiavon, 2009; Schumaher e Brazil, 2000 
Mas talvez a maior transgressão dos abolicionistas tenha sido trazer os próprios escravos para a política. Criaram escolas noturnas para libertos, de que foi o baluarte e modelo o Club dos Libertos de Niterói, gerido por Clapp. Era, em princípio, escola de letras, mas sendo abolicionistas os professores, era também escola de política, muitos entrando escravos e saindo ativistas.

Trazendo outsiders políticos, ex-escravos, mulheres e até crianças para a vida política, o movimento abolicionista desafiou a tradição brasileira, expandindo tanto o público quanto o espectro de agentes sociais praticantes da política.

\section{Oportunidades políticas e ativismo abolicionista}

A Situação Liberal deu oportunidades para o crescimento da mobilização, mas, de outro lado, os 5 gabinetes que governaram o país de 1878 a princípios de 1884 (Sinimbu, Saraiva, Martinho Campos, Paranaguá e Lafayette) pouco fizeram para efetivar a agenda abolicionista. Enquanto os governos patinavam, do lado de fora das instituições, a mobilização seguiu se avolumando. Entre janeiro de 1883 e meados de 1884, deu-se o ápice, um ciclo de protestos (Tarrow, 1995) abolicionista que se espalhou pelo país.

Ciclo esse que tem muito a ver com a Confederação Abolicionista. No ano de seu nascimento, 1883, foram fundadas 41 associações, mais de 3 por mês, quando no ano anterior inteiro surgiram apenas 7; a maioria no Rio, onde a atuação da CA estava sediada. Mas a CA lançou também estratégia de nacionalização do movimento criando uma rede de conexões com abolicionistas das províncias. Nesse ano de 1883, a CA apadrinhou a formação de 2 novas associações em São Paulo, 3 no Rio Grande do Sul, 6 no Ceará e uma no Piauí, Paraná, Espírito Santo e Bahia. Logo depois foi a vez do Mato Grosso e de cidades em São Paulo 
(Campinas; Capava), Rio de Janeiro (Campos, Niterói, Paquetá) e Minas Gerais (Ouro Preto). Eram alianças da CA com abolicionistas locais ou organização de associações conforme seu estilo de ativismo.

A CA também apostou nas conferências-concerto como eventos de mobilização. Entre janeiro de 1883 e maio de 1884, foram 245 eventos $^{7}$, isto é, cerca de 14 por mês ou 3 por semana.

No curso desse ciclo de protestos, o movimento logrou "libertar" a província do Ceará, isto é, comprou alforrias ou obteve libertações voluntárias de todos (ou de quase todos, como denunciaram adversários) os escravos da província, ainda em 1883. Esforços de mesmo sentido renderam idêntico efeito no Amazonas, em 1884, e avançaram, com menor sucesso, para o Rio Grande do Sul (Conrad, 1972) e para cidades estratégicas como Santos e Recife.

O ativismo intenso na Corte e a abolição de fato da escravidão em duas províncias, com a campanha se disseminando noutras, acenderam o sinal vermelho no sistema político, ao enunciar o maior dos terrores da elite política imperial: a possibilidade de fragmentação do país. Não nos moldes norte-americanos de um norte livre versus um sul escravista, mas à maneira da América Espanhola, em um mosaico de muitos retalhos, combinando, em óbvia tensão entre si, províncias escravistas e "libertadas". Essa constatação ativou mudanças no interior do sistema político em 1884.

Se de 1878 a 1884 as oportunidades políticas estimularam o crescimento do ativismo abolicionista, em meados de 1884 foi a mobilização societária que induziu mudanças no sistema político. As instituições responderam ao pico de ativismo de 1883 com a nomeação, em junho de 1884, de gabinete comprometido com a reforma abolicionista, chefiado por Manuel de Souza Dantas, um dos sócios daquela Libertadora Sete de Setembro, de 1869.

7 Dados coligidos a partir de notícias publicadas no jornal Gazeta Tarde, edições de janeiro de 1883 a maio de 1884 . 
A nomeação de Dantas foi ao mesmo tempo resultado da mobilização e propulsor de incremento dela. Entendendo a nova configuração política como vitória sua, o movimento apoiou o governo durante a tramitação do projeto de abolição gradual. De junho de 1884 a maio de 1885, tempo em que Dantas sobreviveu à frente do governo, o movimento tomou as ruas, fazendo não só conferências em teatros, como comícios a céu aberto, de que ficaram memoráveis os de Nabuco no Recife.

Mas como não havia consenso no interior das instituições políticas, nem mesmo dentre os Liberais sobre a forma e o ritmo da abolição, o sistema político digeriu mal o projeto Dantas, que só passou muito alterado (com aumento de 5 anos na idade dos escravos sexagenários a serem libertados e elevação do custo das alforrias), postergando a abolição e derrubando o gabinete. A mobilização das associações abolicionistas no espaço público em apoio ao governo foi insuficiente contra o escravismo politicamente organizado e bem encastelado nas instituições vitalícias, o Senado e o Conselho de Estado.

Perdida a oportunidade da reforma, veio o rebote. O Partido Conservador, que voltou ao governo em 1885 e o reteria até princípios de 1888, freou o reformismo governamental e controlou a sociedade mobilizada pelo mais antigo e efetivo dos meios políticos: a repressão. O governo Conservador desbaratou formal ou informalmente as mobilizações (Toplin, 1972). Fechadas as oportunidades políticas, movimentos sociais tendem a migrar de arena, agindo fora das fronteiras legais (Tilly, Tarrow, McAdam, 2001). Foi o que se passou a seguir, com muitos abolicionistas agindo na clandestinidade, incentivando fugas de escravos (Machado, 1994). A mudança das relações Estado/movimento social em 1885 arrefeceu o ímpeto associativista, com decréscimo de eventos de protesto e de formação de associações.

Daí até o início de 1888, o sistema político, minado antes pela propaganda de rua, atraiu o clamor contrário, dos proprietários de escravos, 
em parte dispostos a coadjuvar a repressão estatal, em parte desacreditados da eficiência do sistema escravista em meio à convulsão social que os abolicionistas promoviam em nível local (Machado, 1994; Toplin, 1972; Conrad, 1972). Dividido entre intensificar a repressão e ceder à reforma - que contava então com apoio explícito da Coroa -, o Partido Conservador trocou o gabinete linha-dura do Barão de Cotegipe por João Alfredo Correia de Oliveira, ministro do governo responsável pelo Ventre Livre.

A mobilização abolicionista tornou a crescer entre março, quando João Alfredo tomou posse, e maio de 1888, quando se aprovou a lei dando cabo na escravidão. Menos movimentação de protesto e mais celebrativa de apoios recebidos em cascata. Foi a hora da "certificação" (Tilly, Tarrow, McAdam, 2001) do abolicionismo pelas elites sociais, que assumiram como sua causa que antes combatiam, ninguém querendo apagar as luzes da escravidão.

\section{Insolidarismo?}

Essa breve reconstrução da história do associativismo abolicionista brasileiro permite voltar ao debate da introdução deste artigo com dois pontos na mão. O primeiro deles é o vigor da auto-organização da sociedade ao largo e mesmo contra as instituições políticas no século 19 brasileiro. Então, em vez do "insolidarismo", que crônica e ciclicamente se projeta para o passado brasileiro, o caso aqui exposto mostra antes a exuberância de uma longeva rede associativa, com capacidade de pressão sobre o sistema político. Do início da campanha até 1888, formaram-se ao menos 207 associações abolicionistas ${ }^{8}$. E os jornais do período dão tes-

8 Este número é superior à soma dos apresentados nos quadros anteriores, porque inclui as associações para as quais não foi possível definir com precisão a província de origem e/ou o ano de fundação. Como a pesquisa ainda está em andamento, é provável que o número total de associações seja ainda superior. 
temunha de uma febre associativa oitocentista, com formação de clubes republicanos, sociedades filantrópicas, científicas, profissionais, educacionais, artísticas e até carnavalescas, como os Tenentes do Diabo.

Tilly (2005, p. 308) argumenta que a Inglaterra no século 18 inventou a forma de protesto "movimento social", precisamente no curso da mobilização contra o tráfico de escravos. Nessa campanha, surgiram várias das formas de mobilização que os movimentos sociais usam até hoje em dia, a popular politics, conjunto de formas variadas de manifestação política no espaço público, como comícios, passeatas e formação de associações (Tilly 2005, p. 308). Por esse critério, a mobilização contra a escravidão nos anos 1880 inaugurou a popular politics ${ }^{9}$ no Brasil. A constituição de sociedades abolicionistas e suas manifestações públicas repetidas, envolvendo uma rede de ativistas e um volume expressivo e diversificado de participantes, agindo coordenadamente no espaço público não parlamentar preenchem o critério. Nesse sentido, o abolicionismo foi o primeiro grande movimento social brasileiro ${ }^{10}$.

9 Tilly define a "popular politics" como "the consequential synthesis of three elements: 1 . a sustained, organized public effort making collective claims on target authorities; let us call it a campaign; 2. employment of combinations from among the following forms of political action: creation de special-purpose associations and coalitions; public meetings; solemn processions; vigils; rallies; demonstrations; petition drives; statements to and in public media; pamphleteering; call the variable ensemble of performances the social movement repertoire; 3 . participants' concerted public representations de WUNC: worthiness, unity, numbers, e commitment on part of themselves and/or their constituencies; call them WUNC displays." (Tilly 2005, p. 308). O conceito de movimento social, portanto, abrange a formação de associações civis como também eventos de mobilização. Neste artigo, privilegiei as associações, não me alongando na apresentação dos eventos de protesto, que, contudo, tratei em texto à parte, Alonso, 2011, e para o qual remeto o leitor.

10 Digo primeiro porque, seguindo a interpretação de Tilly $(1978,2005)$, entendo "movimento social" como a forma moderna de expressão de demandas coletivas ao Estado, que só pode surgir, por definição, depois da consolidação do Estado-nação, processo que, no Brasil, costuma-se datar dos anos 1840, após as rebeliões regenciais e as do início do Segundo Reinado (Bethell e Carvalho, 2009). 
Movimentos sociais não surgem em qualquer circunstância. Tarrow (1998) aponta a correção entre a formação de movimentos e abertura de oportunidades políticas. É precisamente o que se viu aqui, com o ativismo hipertrofiado em períodos de maior permeabilidade do sistema político, e atrofiado quando da alta da repressão.

Meu segundo ponto diz respeito aos partícipes dessa política. Trazendo para a vida política estratos sociais marginalizados pelas instituições políticas imperiais, agregando mulheres, libertos, trabalhadores não qualificados, e mesmo crianças, o movimento brasileiro foi mais inclusivo que as variantes hispânicas, restritas basicamente à classe média (SchmidtNowara,1999).

Tanto em estilo de ativismo quanto em perfil dos mobilizados, o movimento brasileiro se parece mais com os casos britânico e norteamericano, com seu modelo de mobilização de massas urbanas, do que com o francês, centrado no parlamento (Drescher, 1988; Jennings, 2000). Nesse sentido, e independentemente de seus resultados práticos, em vez de confirmar uma endêmica tradição de insolidarismo brasileiro, o movimento abolicionista promoveu, antes, uma democratização da política dentre nós. Mais próximo do que falava Tocqueville do que do que presumiu Oliveira Vianna.

\section{'Avant la lettre' associational activity - antislavery associations in Brazil of the $19^{\text {th }}$ century}

\section{Abstract}

The article challenges the thesis of the weakness of Brazilian associational life in the 1800's, through the analysis of the associations formed in the country to protest against slavery during the second half of the $19^{\text {th }}$ century. Conversely to the thesis of lack of solidarity, the survey on the number of antislavery associations 
created and on the social heterogeneity of their members shows the exuberance of associational civic activity in Imperial Brazil. In addition, the paper argues that shifts toward expansion or decline of antislavery associational activity can be explained by changes in "political opportunities" (Tarrow, 1998).

Keywords: Brazilian associational activity in the $19^{\text {th }}$ century. Antislavery Movement. Political opportunities.

\section{Referências}

Jornais

A Redempção, São Paulo, janeiro de 1887 a maio de 1888.

Cidade do Rio, Rio de Janeiro, outubro de 1887 a maio de 1888.

Gazeta da Tarde, Rio de Janeiro, janeiro de 1883 a dezembro de 1886.

O Abolicionista. Órgão da Sociedade Brasileira Contra a Escravidão, novembro de 1880 a dezembro de 1881. Reproduzido em SILVA, Leonardo Dantas (Org.). Recife: Fundaj; Ed. Massangana, 1988.

Artigos, panfletos e livros

ALONSO, Angela. A teatralização da política: a propaganda abolicionista. Paper apresentado no Seminário Sociologia, História e Política, PPGS-USP, São Paulo, 2010. Disponível em: <http://www.fflch.usp.br/ds/pos-graduacao/downloads/ st_2010_05_angela.pdf $>$.

. Idéias em Movimento: a geração 1870 na crise do Brasil-Império. São Paulo: Anpocs/Paz e Terra, 2002.

. O Abolicionista cosmopolita. Joaquim Nabuco e a rede abolicionista transnacional. Novos Estudos Cebrap, no 88, 2010.

ALVES, Isaias. Vida e Obra do Barão de Macahubas. São Paulo: Companhia Editora Nacional, 1942.

ASSOCIAÇÃO CENTRAL EMANCIPADORA, Boletim n. 8, 20 de março de 1881. AVRITZER, Leonardo. Um desenho institucional para o novo associativismo, Lua Nova, no 39, 1997. 
AZEVEDO, Elciene. Orfeu de carapinha. A trajetória de Luiz Gama na imperial cidade de São Paulo. Campinas: Ed. Unicamp, 1999.

BERGSTRESSER, Rebecca B. The movement for the abolition of slavery in Rio de Janeiro, Brazil. 1880-1889. Stanford University, PhD, 1973.

BETHELL, Leslie; CARVALHO, José Murilo de. O Brasil da Independência a meados do século XIX. In: BETHELL, Leslie (org). História da América Latina. Vol III. Da independência a 1870. Edusp; Funag, 2009.

BETHELL, Leslie. The Abolition of the Brazilian Slave Trade: Britain, Brazil and the slave trade question, 1807-69. Cambridge University Press, 1970.

BEZERRA DE MENEZES, Adolfo, 1869. A Escravidão no Brasil e as medidas que convém tomar para extingui-la sem dano para a nação. Rio de Janeiro: Typ. Progresso, 1869. [Edição fac-similar Bezerra de Menezes, o abolicionista do Império RJ, Associação Editora Espírita F. V. Lorenz, 2007]

BRITO, Jailton Lima. A Abolição na Bahia, 1870-1888. Salvador: Centro de Estudos Baianos da UFBA, 2003.

CANDLER, John; BURGESS, Wilson. Report of the Visit of John Candler and Wilson Burgess to the Brazils in Society of Friends. In: SOCIETY OF FRIENDS. Narrative of the presentation to the sovereigns and those in authority of the address of the yearly meeting on the slave-trade and slavery. London: Editor Eduard Newman, 1854.

CARVALHO, José Murilo de. As conferências radicais do Rio de Janeiro: novo espaço de debate. In: CARVALHO, J. M. (org). Nação e cidadania no Império: novos horizontes. Ed. Civilização Brasileira, 2007.

CASTILHO, Celso T. Abolitionism matters: the politics of antislavery in Pernambuco, Brazil, 1869-1888. Phd dissertation, University of California, Berkeley, 2008.

CONFEDERAÇÃO ABOLICIONISTA. Manifesto da Confederação Abolicionista do Rio de Janeiro [redigido por José do Patrocínio e André Rebouças]. Typografia da Gazeta da Tarde: Rio de Janeiro, 1883.

CONNIFF, Michael L. Voluntary Associations in Rio, 1870-1945: A New Approach to Urban Social Dynamics. Journal of Interamerican Studies and World Affairs, Vol. 17, No. 1, p.64-81, Feb., 1975.

CONRAD, Robert. The destruction of the Brazilian slavery. 1850-1888. University de California Press, 1972.

DANTAS SILVA, Leonardo, A Imprensa e a Abolição. Recife: Editora Massangana, 1988. 
DRESCHER, Seymour. Brazilian Abolition in Comparative Perspective. The Hispanic American Historical Review, Vol. 68, No. 3, p. 429-460, Aug., 1988.

DUQUE ESTRADA, Osório. A Abolição; esboço histórico, 1831-1888. Rio de Janeiro: Leite Ribeiro \& Murillo, 1918.

FERREIRA, Luzilá Gonçalves et al. Suaves Amazonas: mulheres e abolição da escravatura no Nordeste. Recife: Ed. Universitária, UFPE, 1999.

FIGUEROA, Meirevandra Soares. Matéria livre... espírito livre para pensar. Um estudo das práticas abolicionistas em prol da instrução e educação de ingênuos na capital da província sergipana (1881-1884). Dissertação de mestrado, Universidade Federal de Sergipe, 2007.

FONSECA, Luis Anselmo. A escravidão, o clero e o abolicionismo. Ed.fac-similar. Bahia imprensa econômica, 1887. [Ed. Fundaj/Massangana, 1988]

FRICK, João. Abolição da Escravatura. Breve Notícia sobre a Primeira Sociedade de Emancipação no Brasil (fundada na cidade do Rio Grande do Sul em março de 1869). Lisboa: Lallemant Freres, 1885.

GONDRA, José Gonçalves; SAMPAIO, Thiago. Ciência pela força? Dr. Abílio Cesar Borges e a propaganda contra o emprego da palmatória e outros meios aviltantes no ensino da mocidade (1856-1876). Acta Scientiarum. Education Maringá, v. 32, n. 1, p. 75-82, 2010.

GRADEN, D. T. From slavery to freedom in Brazil. Bahia, 1835-1900. Univ. of New Mexico Press, 2006.

HAHNER. June. Emancipating the female sex. The struggle for women's rights in Brazil 1850-1940. Duke Univ. Press, 1990.

JENNINGS, Lawrence C. French Anti-Slavery: The Movement for Abolition of Slavery in France, 1802-1848. Cambridge: Cambridge UP, 2000.

JESUS, Ronaldo Pereira de. Associativismo no Brasil do Século XIX: repertório crítico dos registros de sociedades no Conselho de Estado (1860-1889). Locus: revista de história, Juiz de Fora, v. 13, n. 1, 2007.

KITTLESON, Roger A. The Practice of Politics in Postcolonial Brazil: Porto Alegre, 1845-1895. University of Pittsburgh Press, 2005.

KODAMA, Kaori. Os debates pelo fim do tráfico no periódico O Philantropo (1849-1852) e a formação do povo: doenças, raça e escravidão. Revista Brasileira de História, vol. 28, no 56, 2008.

LONER, Beatriz Ana. Negros: organização e luta em Pelotas. História em Revista, v. 5 Pelotas, p.7-27, 1999. 
MACHADO, Maria Helena. O plano e o pânico: os movimentos sociais na década da abolição. Rio de Janeiro: UFRJ; Edusp, 1994.

McADAM, D. Biographical consequences of activism. American Sociological Review, 54, p. 744-760, 1989.

MCADAM, D.; TARROW, S.; TILLY, C. Dynamics of contention. New York: Cambridge University Press, 2001.

MORAES, Evaristo. A Campanha Abolicionista (1879-1888). Brasília: Ed.UnB, 1986 (1924).

MOREIRA DE AZEVEDO, Duarte. Sociedades fundadas no Brasil desde os tempos coloniais até o começo do atual reinado. Memória lida nas sessões do Instituto Histórico em 1884, Revista do IHGB ,48, 2, 1885.

MOREL, Edmar. Vendaval da liberdade. São Paulo: Editora Global, 1988.

MOTT, Maria Lúcia. Submissão e Resistência; a mulher na luta contra a escravidão. São Paulo: Ed. Contexto. 1988.

MOURA, Clóvis. Dicionário da escravidão negra. São Paulo: Edusp, 2004.

NABUCO, Joaquim.. Minha Formação. São Paulo: W. M. Jackson Inc. Editores. 1949 [1900].

NEEDELL, Jeffrey. Brazilian Abolitionism, Its Historiography, and the Uses of Political History . Journal of Latin American Studies, Volume 42, Issue 02, 2010.

ROLIM, I. E. (coord). A Saga da Abolição Mossoroense, livro I. Edição especial para o Acervo Virtual Oswaldo Lamartine de Faria, 2002. Disponível em: < http:// www.colecaomossoroense.org.br $>$.

SANTOS, Wellington Barbosa dos. Confederações abolicionistas no Maranhão na segunda metade do séc. XIX (1870-1888). São Luís: UEMA, 2008. Monografia (Graduação), Curso em História, Universidade Estadual do Maranhão, 2008.

SCHIAVON, Carmem G. Burgert. A Primeira Sociedade de Emancipação de Escravos do Brasil 2009. Paper apresentado 4ㅇ․ Encontro Escravidão e Liberdade no Brasil Meridional, Curitiba, maio de 2009.

SCHMIDT-NOWARA, Christopher. Empire and Anti-Slavery: Spain, Cuba, and Porto Rico, 1833-1874. Pittsburgh: University of Pittsburgh Press, 1999.

SCHUMAHER, Schuma; BRAZIL, Érico Vital (Orgs.). Dicionário Mulheres do Brasil. Rio de Janeiro: Jorge Zahar, 2000.

SCTAPCCI (Sociedade Contra o Tráfico de Africanos e Promotora da Colonização e da Civilização dos Indígenas). Sistema de medidas adotáveis para a progres- 
siva e total extinção do trafico, e da escravatura no Brasil confeccionado e aprovado pela Sociedade contra o trafico de africanos, e promotora da colonisação, e da civilizarão dos indígenas. Rio de Janeiro, 1852.

SILVA, Eduardo. As camélias do Leblon e a abolição da escravatura - uma investigação de história cultural. São Paulo: Companhia das Letras, 2003.

SOARES, Caetano Alberto. Memória para melhorar a sorte dos nossos escravos. Lida na sessão geral do Instituto dos Advogados Brasileiros, no dia 7 de setembro de 1845, pelo Dr. Caetano Alberto Soares. Rio de Janeiro: Typ. Imparcial de Francisco de Paula Brito, 1847.

TARROW, Sidney. Cycles of collective action: between moments of madness and the repertoire of contention. In: TRAUGOTT, Mark (ed). Repertoires and cycles of collective action. Duke University Press, 1995.

Power in Movement. Social movements and contentious politics. Cambridge: Cambridge Univ. Press. 1998.

. Dynamics of diffusion: mechanisms, institutions, and scale shift. In: GIVAN, Rebecca Kolins; ROBERTS, Kenneth M.; SOULE, Sarah A. The diffusion of social movements: actors, mechanisms, and political effects. Cambridge: Cambridge University Press, 2010.

TILLY, Charles.. Introduction to Part II: Invention, Diffusion, and Transformation of the Social Movement Repertoire. European Review de History: Revue europeenne d'histoire, 12: 2, p. 307-320, 2005.

TOPLIN, Robert. The Abolition of Slavery in Brazil. New York: Atheneum, 1972. VIANNA, Francisco José de Oliveira. Populações Meridionais do Brasil. Rio de Janeiro: Paz e Terra;Governo do Estado do Rio de Janeiro/UFF, 1973 [1920].

XAVIER, Janaina Silva. Saneamento de Pelotas (1871-1915): o patrimônio sob o signo de modernidade e progresso. Pelotas: UFPEL, 2010. 355f. Dissertação Mestrado em Memória Social e Patrimônio Cultural, Universidade Federal de Pelotas, 2010.

Recebido em: 03/06/2011

Aceite final: 05/08/2011 